\title{
The selective inhibition of protein phosphatase-1 results in mitotic catastrophe and impaired tumor growth
}

\author{
Claudia Winkler, Sofie De Munter, Nele Van Dessel, Bart Lesage, Ewald Heroes, Shannah Boens, \\ Monique Beullens, Aleyde Van Eynde and Mathieu Bollen*
}

\begin{abstract}
The serine/threonine protein phosphatase-1 (PP1) complex is a key regulator of the cell cycle. However, the redundancy of PP1 isoforms and the lack of specific inhibitors have hampered studies on the global role of PP1 in cell cycle progression in vertebrates. Here, we show that the overexpression of nuclear inhibitor of PP1 (NIPP1; also known as PPP1R8) in HeLa cells culminated in a prometaphase arrest, associated with severe spindle-formation and chromosome-congression defects. In addition, the spindle assembly checkpoint was activated and checkpoint silencing was hampered. Eventually, most cells either died by apoptosis or formed binucleated cells. The NIPP1-induced mitotic arrest could be explained by the inhibition of PP1 that was titrated away from other mitotic PP1 interactors. Consistent with this notion, the mitoticarrest phenotype could be rescued by the overexpression of PP1 or the inhibition of the Aurora B kinase, which acts antagonistically to PP1. Finally, we demonstrate that the overexpression of NIPP1 also hampered colony formation and tumor growth in xenograft assays in a PP1-dependent manner. Our data show that the selective inhibition of PP1 can be used to induce cancer cell death through mitotic catastrophe.
\end{abstract}

KEY WORDS: Cell death, Mitotic catastrophe, NIPP1, Protein phosphatase-1, Tumor growth

\section{INTRODUCTION}

Cell cycle progression is tightly controlled through reversible phosphorylation of key regulators by a variety of protein kinases and phosphatases (Novak et al., 2010; Qian et al., 2013a). One of the cell-cycle-regulating enzymes is the serine/threonine protein phosphatase-1 (PP1) a ubiquitously expressed and conserved member of the phosphoprotein phosphatase (PPP) superfamily (Heroes et al., 2013). PP1 forms heterodimeric or heterotrimeric complexes with $>200$ PP1-interacting proteins (PIPs), which function as substrate-targeting or -specifying subunits and activity regulators. PP1 has established substrates in all phases of the cell cycle, including the retinoblastoma protein in the G1 phase (Ludlow et al., 1993), the helicase MCM4 in S-phase (Hiraga et al., 2014), protein phosphatase Cdc25 in G2 phase (Margolis et al., 2006) and protein kinases Aurora A and Aurora B in M-phase (Bollen et al., 2009).

In invertebrates, the deletion of PP1 or its most abundant isoform causes a mid-mitotic arrest that is associated with an abnormal

Laboratory of Biosignaling \& Therapeutics, KU Leuven Department of Cellular and Molecular Medicine, University of Leuven, Leuven B-3000, Belgium.

*Author for correspondence (Mathieu.Bollen@med.kuleuven.be)

Received 10 June 2015; Accepted 26 October 2015 spindle organization and over-condensed chromosomes (Axton et al., 1990; Chen et al., 2007; Doonan and Morris, 1989; Hisamoto et al., 1994). In addition, the spindle assembly checkpoint (SAC), which prevents the onset of anaphase until all chromosomes are properly aligned and bioriented, is activated for a prolonged time (Ohkura et al., 1989; Sassoon et al., 1999). Moreover, in those cells where the SAC is eventually satisfied, the checkpoint cannot be turned off in the absence of kinetochore-associated PP1 (Meadows et al., 2011; Pinsky et al., 2009; Rosenberg et al., 2011; Vanoosthuyse and Hardwick, 2009). It is not clear whether the deletion or inhibition of PP1 also causes a similarly strong mitoticarrest phenotype in vertebrate cells. Various PIPs mediate the interaction of PP1 with the centrosomes, spindle and mitotic chromosomes in vertebrates, including CENP-E (Kim et al., 2010), Kif18A (Häfner et al., 2014), KNL1 (Espert et al., 2014; Liu et al., 2010; Nijenhuis et al., 2014), RepoMan (also known as CDCA2) (Qian et al., 2013b; Vagnarelli et al., 2011; Wurzenberger et al., 2012) and Sds22 (Eiteneuer et al., 2014; Wurzenberger et al., 2012). These mitotic pools of PP1 holoenzymes have functions throughout the M-phase. Nevertheless, the overall contribution of PP1 to cell cycle progression in vertebrates, and cell division in particular, remains poorly understood. The injection of inhibitory anti-PP1 antibodies into early mitotic mammalian fibroblasts has been reported to cause a metaphase arrest (Fernandez et al., 1992), but the effects on other stages of the cell cycle were not investigated. The knockdown of PP1 $\gamma$ had no effect on the mitotic spindle but caused a cytokinesis defect and the formation of dikaryons (Cheng et al., 2000).

In general, it has been rather challenging to delineate the contribution of PP1 to cell cycle progression in vertebrates, mainly because of the lack of specific cell-permeable inhibitors. Another problem stems from the functional redundancy between PP1 isoforms, making knockdown experiments of individual isoforms rather uninformative (Cheng et al., 2000; Kirchner et al., 2007; Trinkle-Mulcahy et al., 2006; Varmuza et al., 1999). We have delineated the global role of PP1 in cell cycle progression using cell lines that inducibly overexpress nuclear inhibitor of PP1 (NIPP1; also known as PPP1R8). NIPP1 is a very potent and highly specific inhibitor of PP1, and prevents the dephosphorylation of all tested protein substrates by associated PP1, except for phosphoproteins that are recruited through the NIPP1 N-terminal forkheadassociated (FHA) domain (Beullens et al., 1992; Vulsteke et al., 1997). Hence, when the phosphate-binding loop in the FHA domain is mutated, NIPP1 can be used as a highly selective inhibitor of PP1. Here, we show that the expression of NIPP1 causes spindleassembly and chromosome-congression defects, and a prolonged SAC that often culminates in cell death. We also demonstrate that this arrest is entirely dependent on the ability of NIPP1 to bind PP1 and is largely explained by the removal of PP1 from other mitotic PIPs. Our data show that the global inhibition of PP1 kills dividing 
A
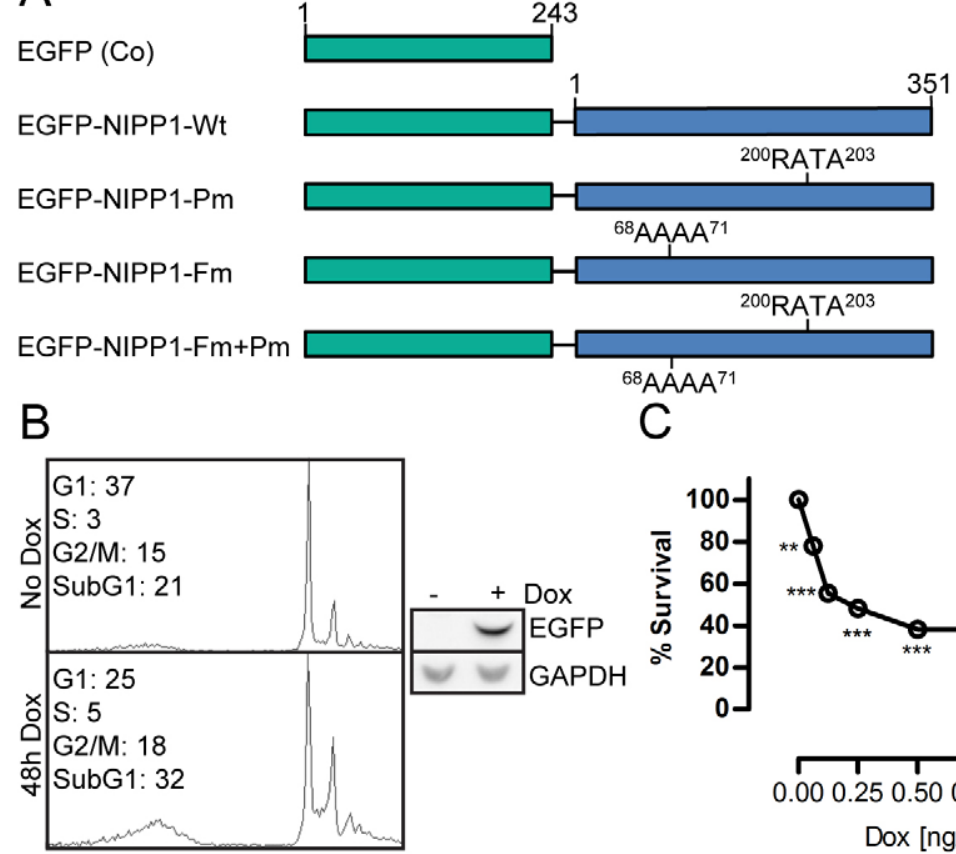

D

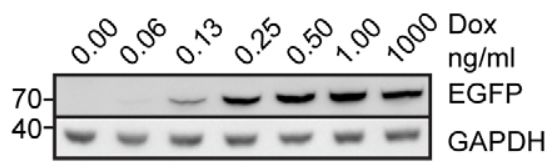

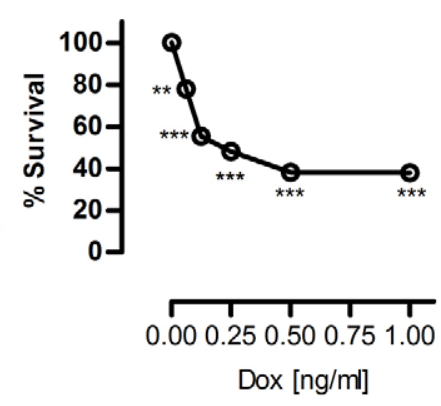

$E$

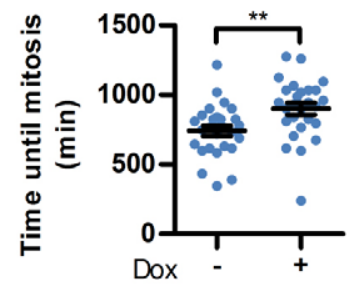

Fig. 1. The overexpression of NIPP1 causes cell death. (A) Schematic representation of the NIPP1 fusions used for generating stable Flp-In TREx HeLa cell lines. (B) FACS analysis showing cell cycle distribution of asynchronous HeLa cells before and after the induction of NIPP1-Wt expression. Also shown is an immunoblot for the EGFP fusion in a representative lysate. GAPDH served as a loading control. (C) Cell survival was calculated from sulforhodamine B assays after the induction of NIPP1-Wt expression with the indicated Dox concentrations. Data are presented as means \pm s.e.m. $(n=3) .{ }^{* *} P<0.01 ;{ }^{* * *} P<0.001$ (Student's $t$-test).

(D) Immunoblots for the EGFP fusions in representative lysates. GAPDH served as a loading control. (E) Time until mitosis after release from a thymidine arrest, as measured by DIC time-lapse imaging. Data are mean \pm s.e.m. ( $n=30$ cells). ${ }^{* *} P<0.01$ (Student's $t$-test). cancer cells and suggest that mitotic PP1 holoenzymes are potential targets for a novel cancer therapy.

\section{RESULTS}

The overexpression of NIPP1 causes an arrest in mitosis and cell death

To delineate the role of PP1 in cell cycle progression we generated HeLa cell lines that inducibly express EGFP [denoted EGFP (Co)] or fusions of EGFP with the PP1 inhibitor NIPP1, using the Flp-In T-REx system. In addition to a fusion with wild-type NIPP1 (NIPP1-Wt), we engineered NIPP1 fusions with a non-functional substrate-binding FHA domain (NIPP1-Fm), a mutated RVxF-type PP1-binding site (NIPP1-Pm), and the combined mutations (NIPP1-Fm+Pm) (Fig. 1A). The cell lines expressed the fusions in a doxycycline (Dox)-dependent manner and to a similar extent (Figs S1A and S2A). As expected (Tanuma et al., 2008; Van Dessel et al., 2010), EGFP traps of the NIPP1-Wt and NIPP1-Fm fusions showed an association with endogenous PP1, which was not seen with the NIPP1-Pm and NIPP1-Fm+Pm fusions (Figs S1B and S2B). The associated PP1 was inactive with glycogen phosphorylase as substrate but the phosphatase activity could be revealed by trypsinolysis, which destroys NIPP1 but not PP1 (Beullens et al., 1998), confirming that NIPP1-Wt and NIPP1-Fm inhibit PP1 (Fig. S1C). In addition, the NIPP1-Wt and NIPP1-Pm fusions co-precipitated with Sap155, a pre-mRNA splicing factor that is an established NIPP1-FHA ligand (Fig. S1D). Such coprecipitation was not seen with NIPP1-Fm, the FHA-ligand binding mutant. Finally, the targeting of NIPP1 to splicing-factor storage sites or nuclear speckles, which is also mediated by the FHA domain (Jagiello et al., 2000), was not detected with the NIPP1-Fm and NIPP1-Fm+Pm fusions (Figs S1E and S2C). Collectively, these data show that EGFP-NIPP1 has the same ligand-binding properties as endogenous NIPP1 and validate EGFP-NIPP1-Pm and EGFP-NIPP1-Fm as PP1- and substrate-binding mutants, respectively.

FACS analysis of non-synchronized cells revealed that the expression of NIPP1-Wt caused an accumulation of cells with fragmented chromatin (increased sub-G1 fraction), hinting at increased cell death (Fig. 1B). Sulforhodamine B colorimetric assays confirmed that there was a reduced cell survival that depended on the concentration of ectopically expressed NIPP1-Wt (Fig. 1C,D). To examine whether overexpressed NIPP1-Wt induced cell death in a specific phase of the cell cycle, we performed live-cell imaging with differential interference contrast (DIC) microscopy. The time to mitotic entry after thymidine release amounted to $742 \pm$ $36 \mathrm{~min}$ in non-induced and $900 \pm 42 \mathrm{~min}$ in NIPP1-Wt-expressing cells (mean \pm s.e.m, $n=30$ ), suggesting a modest mitotic entry delay in the induced cells (Fig. 1E). However, during this period no DNA damage was detected, as shown by $\gamma \mathrm{H} 2 \mathrm{Ax}$ stainings (Fig. S2D), and $92 \%$ of the NIPP1-Wt-expressing cells entered mitosis. Thus, the induction of NIPP1-Wt did not have major effects on progression through interphase and mitotic entry.

Time-lapse imaging of selected EGFP-expressing cells after the removal of thymidine did reveal, however, a strong mitotic-arrest phenotype after the induction of either the NIPP1-Wt or NIPP1-Fm fusions (Fig. 2A). In these conditions few cells spent less than $2 \mathrm{~h}$ in 
A

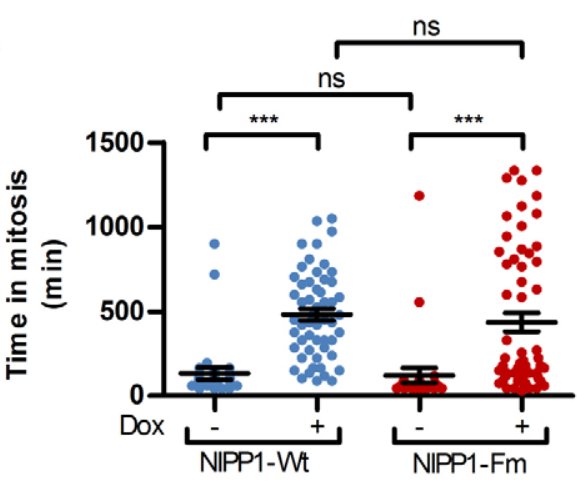

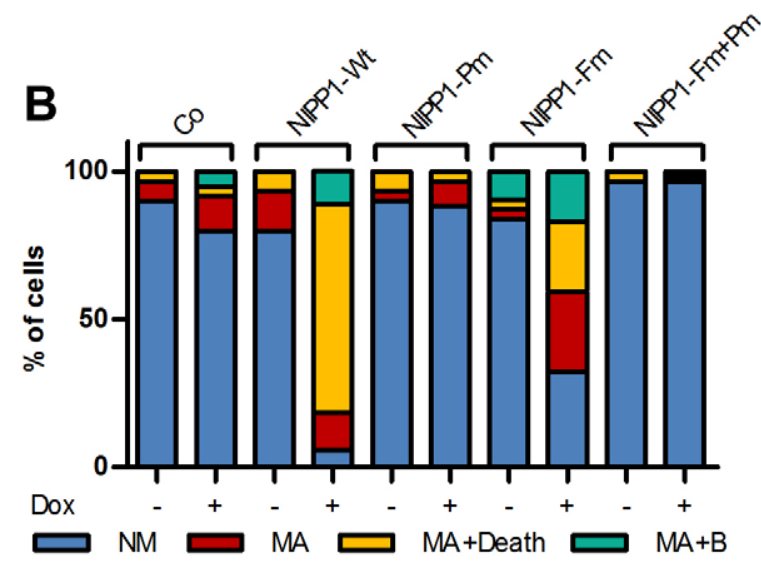

C

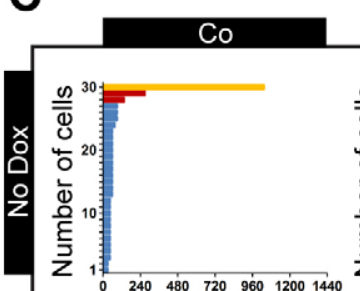

NIPP1-Wt

NIPP1-Pm
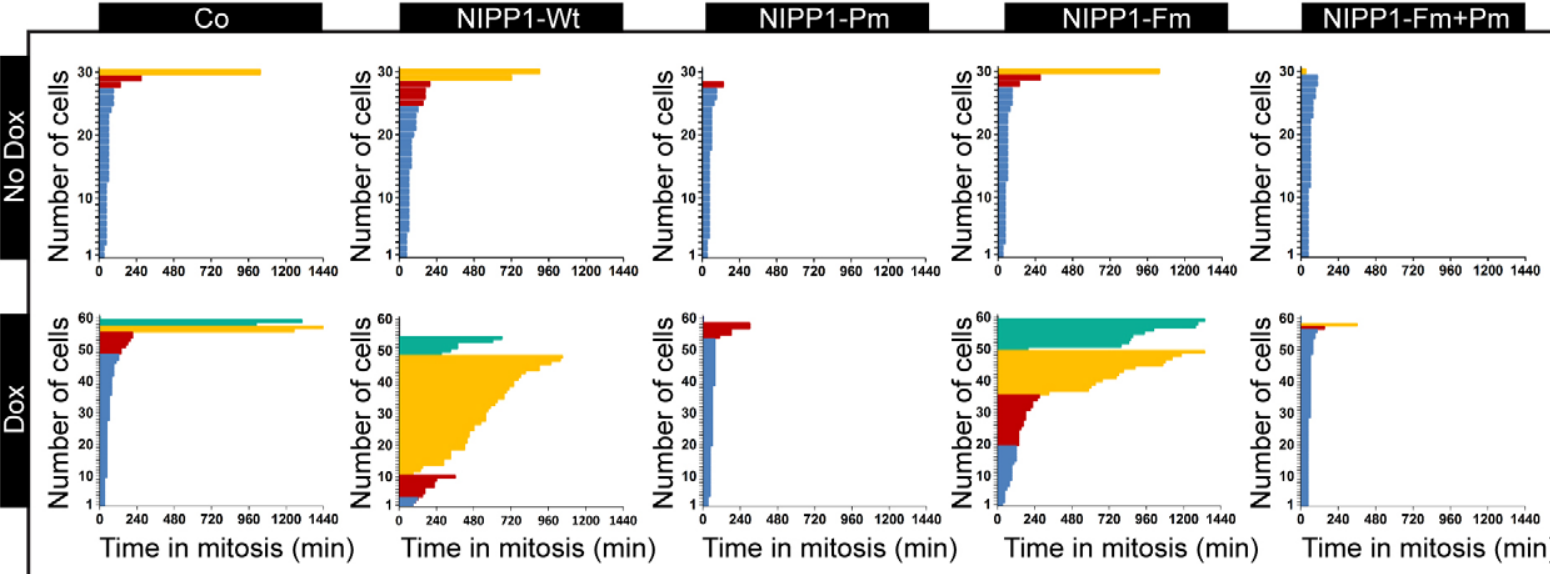

NM

$\square$ MA

MA+Death

$M A+B$

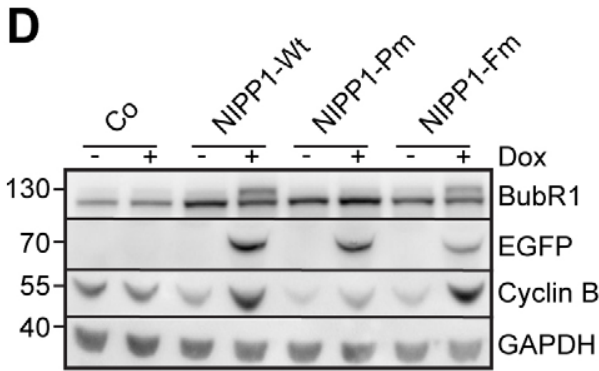

E

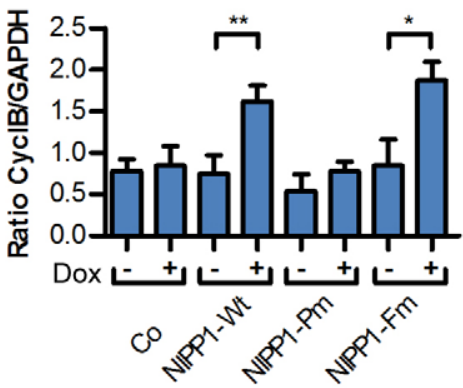

Fig. 2. The overexpression of NIPP1 causes an arrest in mitosis. (A) Duration of mitosis in non-induced or induced NIPP1-Wt and NIPP1-Fm cell lines, as measured by DIC time-lapse imaging. The bars represent means \pm s.e.m. About 50 cells were analyzed for each condition. ${ }^{* * *} P<0.001 ; n s$, not significant (Student's $t$-test). Cells were synchronized with a double thymidine block and after an $8 \mathrm{~h}$ release, time-lapse imaged for $60 \mathrm{~h}$. (B) The fate of the stable cells in mitosis. NM, normal mitosis ( $<2 \mathrm{~h}$ ); MA, mitotic arrest ( $>2 \mathrm{~h}$ ); MA+Death, mitotic arrest followed by apoptosis; MA+B, mitotic arrest leading to binucleation. The bar diagrams show percentages of cells with the stated phenotype. (C) Same as in B but each horizontal line represents the time in mitosis of an individual cell. (D) Immunoblotting of the indicated proteins in cell lysates. The expression of the fusion proteins (not shown for Co) was confirmed with anti-EGFP antibodies. GAPDH served as a loading control. The mitotic phenotypes described in B-E were obtained with two independent clones of each stable cell line (data not shown). (E) Cyclin B:GAPDH ratios for the same conditions. The data represent mean \pm s.e.m. $(n=3)$. ${ }^{*} P<0.05$; ${ }^{* *} P<0.01$ (Student's $t$-test).

mitosis, which was considered a normal length of mitosis. Instead, the NIPP1-Wt- or NIPP1-Fm-expressing cells often showed a mitotic arrest that culminated in (1) an apparently normal mitotic exit, (2) the formation of binucleated cells, or (3) cell death (Fig. 2B,C). Cell death was associated with membrane blebbing (Movies 1-5) and the accumulation of caspase-3 (Fig. S1F). Importantly, cell death did not occur when the cells were blocked in the G1/S or G2 phases of the cell cycle with thymidine or RO-3306, respectively (data not shown), indicating that cells underwent cell death during mitosis. In general, the mitotic-arrest phenotypes were somewhat stronger with NIPP1-Wt- than with NIPP1-Fm-expressing cells (Fig. 2A-C), hinting at a contribution of a functional FHA domain. 
However, the mitotic-arrest phenotype was completely absent after the expression of NIPP1-Pm or NIPP1-Fm+Pm (Fig. 2B,C), showing that it was entirely dependent on the ability of NIPP1 to bind PP1. Finally, a mitotic arrest in the NIPP1-Wt- or NIPP1-Fmexpressing cells was biochemically confirmed by immunoblotting, showing an accumulation of the mitotic regulators cyclin B and phosphorylated (mobility shifted) BubR1 (Fig. 2D,E).

\section{The mitotic phenotype stems from a prometaphase arrest and a persistently active SAC}

To determine at which mitotic stage the NIPP1-Wt- or NIPP1-Fmexpressing cells were blocked, they were followed by time-lapse imaging after the transient expression of Cherry-tagged histone H2B (Fig. 3A,B; Movies 6-9). This analysis revealed that 95\% of NIPP1-Wt- and $\sim 75 \%$ of NIPP1-Fm-expressing cells failed to align their chromosomes at the metaphase plate and spent a prolonged time in prometaphase. Some cells aligned their chromosomes at the metaphase plate for a short period, but then regressed to a prometaphase-like stage. Quantification of the number of cells in prometaphase, metaphase and anaphase plus telophase after fixation confirmed a prometaphase arrest after the induction of NIPP1-Wt or NIPP1-Fm expression (Fig. S3).

To delineate the cause(s) of the prometaphase arrest, we first examined spindle organization by staining fixed cells for $\alpha$-tubulin and the centrosomal marker centrobin. This revealed major spindle defects in NIPP1-Wt- or NIPP1-Fm-expressing cells. For NIPP1Wt these defects included aberrant and elongated spindles with unfocused spindle poles (Fig. 3C,D). NIPP1-Fm-expressing cells also showed elongated spindles, but the spindle poles were focused. In addition, a significantly longer pole-to-pole distance was measured in NIPP1-Wt- or NIPP1-Fm-expressing cells, indicating that there were microtubule dynamics defects (Fig. 3E). We also often noticed chromosome-congression defects (Fig. 3C). To quantify the latter defects, cells were first blocked in prometaphase with monastrol, resulting in the formation of monopolar spindles, and then allowed to progress to metaphase by the removal of monastrol in the presence of the proteasome inhibitor MG132. In these conditions, $\sim 95 \%$ of the NIPP1-Wtexpressing cells and $\sim 75 \%$ of the NIPP1-Fm-expressing cells showed chromosome misalignments, as compared to only $\sim 10 \%$ without prior induction of the transgenes (Fig. 3F,G).

Problems with spindle organization or chromosome congression are known to cause an activation of the SAC (Lesage et al., 2011). Consistent with SAC activation, we found that NIPP1-Wt- or NIPP1-Fm-expressing cells were enriched for hyperphosphorylated BubR1, a SAC component (Fig. 2D). Moreover, BubR1 was enriched at the kinetochores in these cells (Fig. 4A). In addition, NIPP1-Wt overexpressing cells only showed a partial recovery from a mitotic arrest following the washout of the cyclin dependent kinase 1 (Cdk1) inhibitor R0-3306 (Fig. 4B). However, in these experiments the mitotic index was normalized after the prior knockdown of Mad2, an essential SAC component (Maldonado and Kapoor, 2011), indicating that the overexpression of NIPP1-Wt prevents the progression through mitosis because of a persistently active SAC.

Given that PP1 contributes to SAC inactivation in yeast (London et al., 2012; Meadows et al., 2011; Pinsky et al., 2009; Rosenberg et al., 2011; Tang and Toda, 2015; Vanoosthuyse and Hardwick, 2009), we have also examined whether the NIPP1-Wt or NIPP1-Fm overexpressing cells have a skewed SAC silencing. Therefore, we performed SAC override assays (Santaguida et al., 2011) and measured the time to complete mitosis, as detected by the loss of cell rounding, after the inhibition of SAC activation in prometaphase-arrested cells with the Aurora inhibitor hesperadin or the MPS1 inhibitor reversine (Fig. 4C). With both inhibitors, the override time was significantly increased after the expression of either NIPP1-Wt or NIPP1-Fm, hinting at a problem with SAC silencing.

\section{The mitotic-arrest phenotype stems from the inhibition of PP1}

Full-length NIPP1 binds to PP1 with an extremely high affinity and inhibits the phosphatase towards all tested protein substrates except FHA ligands (Beullens et al., 2000; O'Connell et al., 2012; Tanuma et al., 2008). Given that the mitotic-arrest phenotype induced by the overexpression of NIPP1 was entirely dependent on a functional PP1-binding site, we reasoned that the phenotype could be caused by titrating PP1 away from other PIPs. Consistent with this notion, we found that the typical nucleolar enrichment of PP1 $\gamma$ was largely lost by the induction of NIPP1-Wt or NIPP1-Fm, but not by the expression of NIPP1-Pm (Fig. 5A). This suggests that overexpressed NIPP1, which is itself nuclear but excluded from the nucleoli, successfully competed with nucleolar-targeting subunit(s) for binding to PP1. Likewise, following the expression of NIPP1-Wt or NIPP1-Fm, considerably less PP1 activity co-precipitated with endogenous Ki67, RepoMan and Kif18A in prometaphase-arrested cells (Fig. 5B), indicating that NIPP1-Wt and NIPP1-Fm competitively removed PP1 from these mitotic PIPs (Booth et al., 2014; Häfner et al., 2014; Takagi et al., 2014; Vagnarelli et al., 2011). This was confirmed for RepoMan by immunoblotting (Fig. S4A). Ki67 and Kif18A are themselves substrates for associated PP1 (Häfner et al., 2014; Takagi et al., 2014). We noted that the expression of NIPP1-Wt or NIPP1-Fm, but not NIPP1-Pm, reduced the mobility of Ki67 and Kif18A, during SDSPAGE (Fig. S4B-D), consistent with hyperphosphorylation, as expected from their reduced association with PP1. Finally, we observed a partial delocalization of Aurora B in mitotically arrested cells that expressed NIPP1-Wt or NIPP1-Fm (Fig. 5C,D). Indeed, in these cells the centromeric localization of Aurora B, which is known to be dependent on PP1 (Qian et al., 2011), was partially lost and showed instead a more diffuse distribution.

If the mitotic arrest induced by the overexpression of PP1-binding NIPP1 variants is caused by the inhibition of PP1 pools that are essential for mitosis, one would expect a (partial) rescue of this phenotype upon the overexpression of PP1. We indeed observed that the ectopic expression of RFP-PP1 $\gamma$ in the NIPP1-Fmexpressing cell line reduced the number of cells with a mitotic arrest (Fig. 6A; Fig. S4E). It also decreased the average duration of mitosis (Fig. 6B), as measured by time-lapse imaging. The rescue was proportional to the amount of expressed RFP-PP1. In addition, when the NIPP1-Fm-expressing cells were first synchronized with thymidine and then released for $18 \mathrm{~h}$, a mitotic arrest was evident from the accumulation of cyclin $\mathrm{B}$, but this phenotype was rescued by the expression of Flag-PP1 $\gamma$ (Fig. 6C,D). Finally, the SAC inactivation defect could also be partially rescued by the expression of RFP-PP1 $\gamma$ (Fig. S4F).

PP1 antagonizes the Aurora A and B kinases, both by inactivating the kinases themselves and by dephosphorylating their substrates (for reviews, see Bollen et al., 2009; Wurzenberger and Gerlich, 2011). Therefore, we speculated that the mitotic arrest and death phenotype induced by the selective inhibition of PP1 should be (partially) reversed by inhibition of the Aurora kinases. To test this hypothesis, we made use of our observation that NIPP1-Fm reduced cell survival, as determined by sulforhodamine B assays (Fig. 6E). 

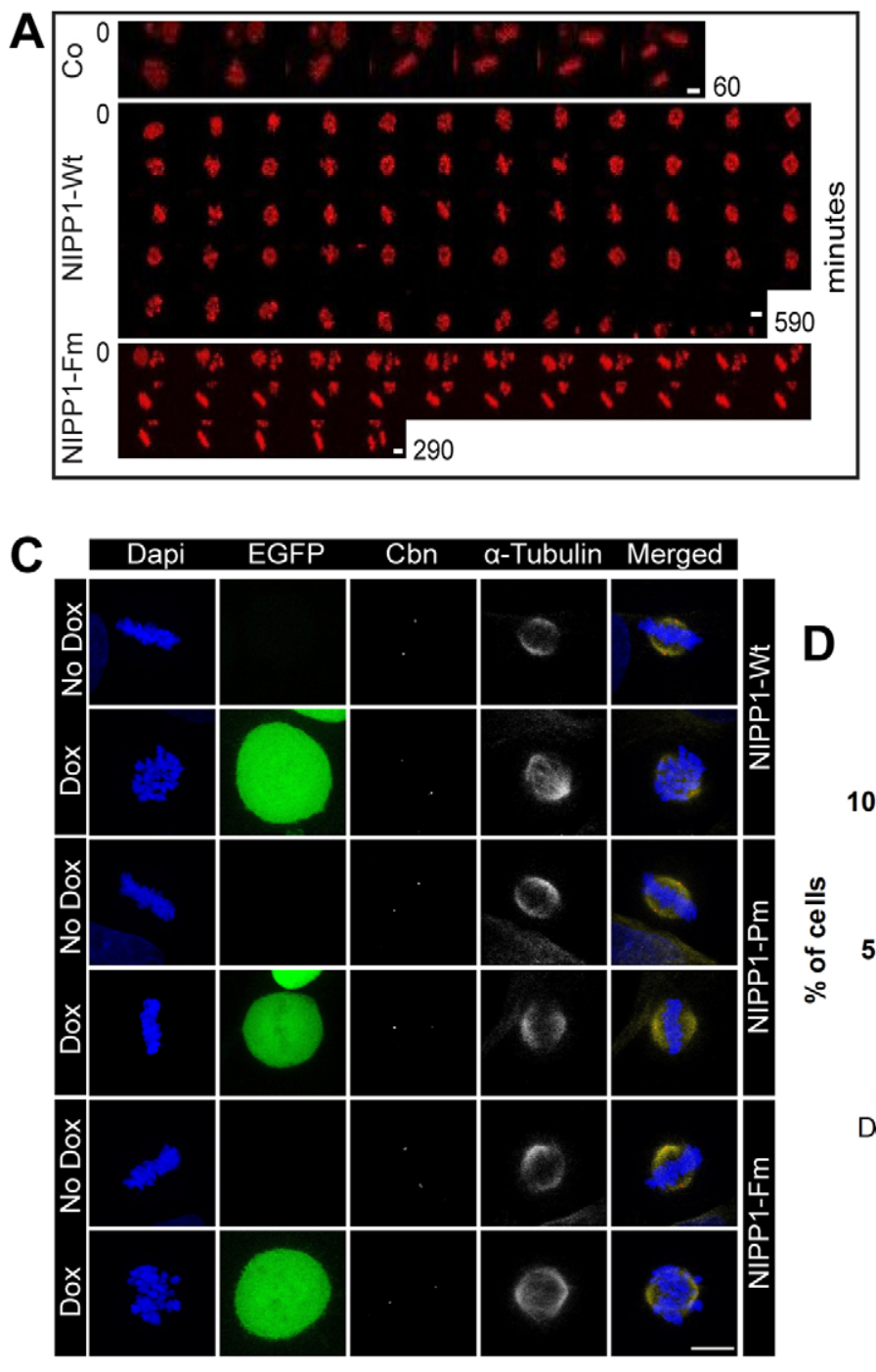

B

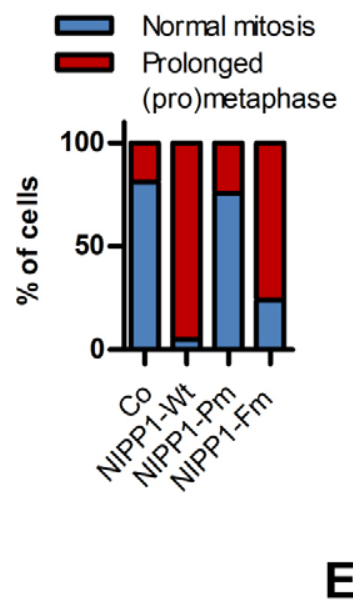

$\mathbf{E}$

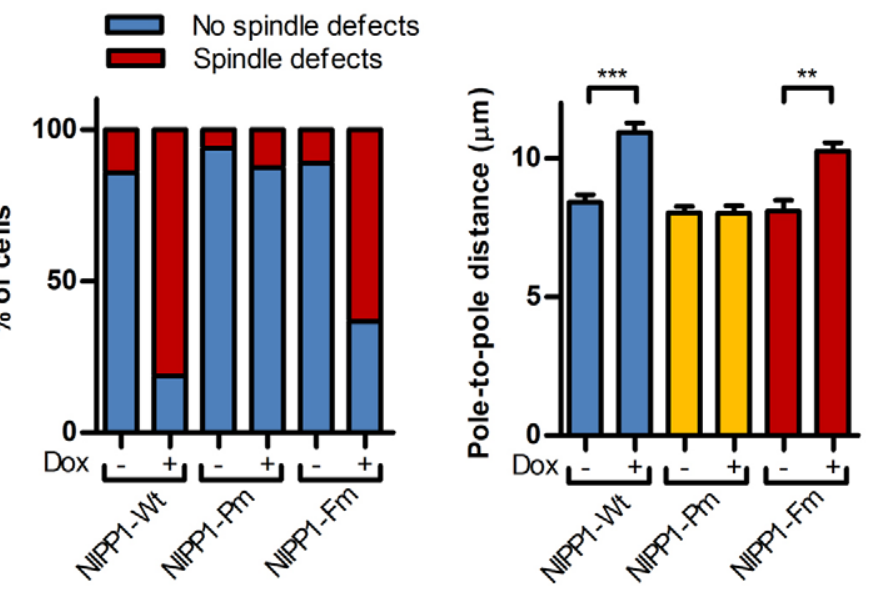

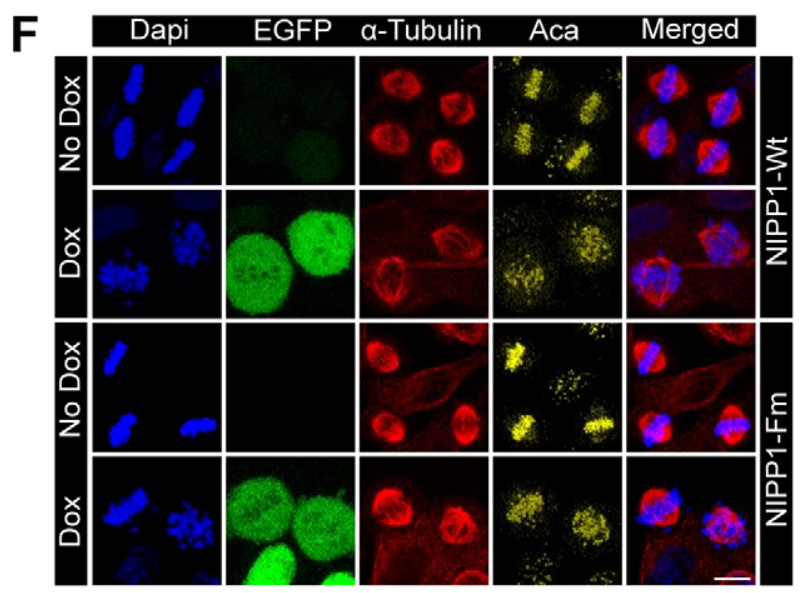

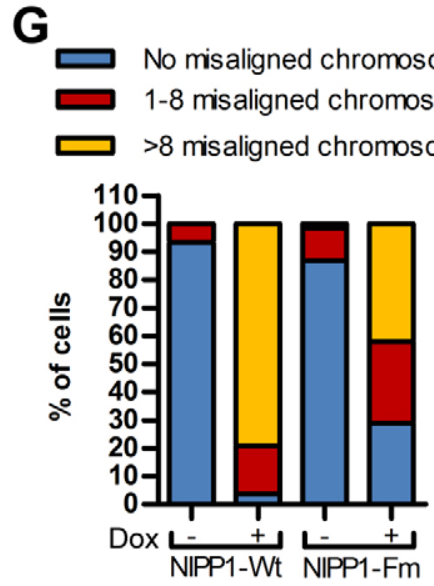

Fig. 3. The mitotic phenotypes in NIPP1-overexpressing cells stem from a prometaphase arrest. (A) The induced stable cell lines were transiently transfected with Cherry-histone-H2B and followed by time-lapse imaging. The figure shows representative montages (images were taken at 10-min intervals) for mitotic control cells (Co) as well as cells expressing NIPP1-Wt or NIPP1-Fm. The montages stop at the stage when cells underwent cytokinesis (Co or NIPP1-Fm) or apoptosis (NIPP1-Wt). Scale bar: $10 \mu \mathrm{m}$. (B) Quantification of cells with a prolonged (pro)metaphase (>100 min). About 40 cells were analyzed by time-lapse imaging for each condition. (C) Staining for DNA (DAPI), centrobin (Cbn) and $\alpha$-tubulin in the Flp-In T-REx cell lines in the absence or presence of Dox,

showing spindle defects after the expression of NIPP1-Wt or NIPP1-Fm. Scale bar: $10 \mu \mathrm{m}$. (D) Quantification of the spindle defects, as illustrated in C ( $n=40 \mathrm{cells}$ ). (E) The pole-to-pole distance was measured before and after induction of NIPP1-Wt or NIPP1-Fm. Data are represented as means \pm s.e.m. $(n=40 \mathrm{cells}) .{ }^{* *} P<0.01$; ${ }^{* * *} P<0.001$ (Student's $t$-test). (F) Non-induced and induced NIPP1-Wt- or NIPP1-Fm-expressing cells were blocked for $8 \mathrm{~h}$ in $100 \mathrm{nM}$ monastrol and released for $90 \mathrm{~min}$ in $20 \mu \mathrm{M}$ MG132. The figure shows immunostainings for $\alpha$-tubulin, a centromeric marker (Aca), and EGFP fluorescence. Scale bar: $10 \mu \mathrm{m}$. (G) Quantification of the observed chromosome misalignments, as illustrated in F ( $n=400$ cells). 


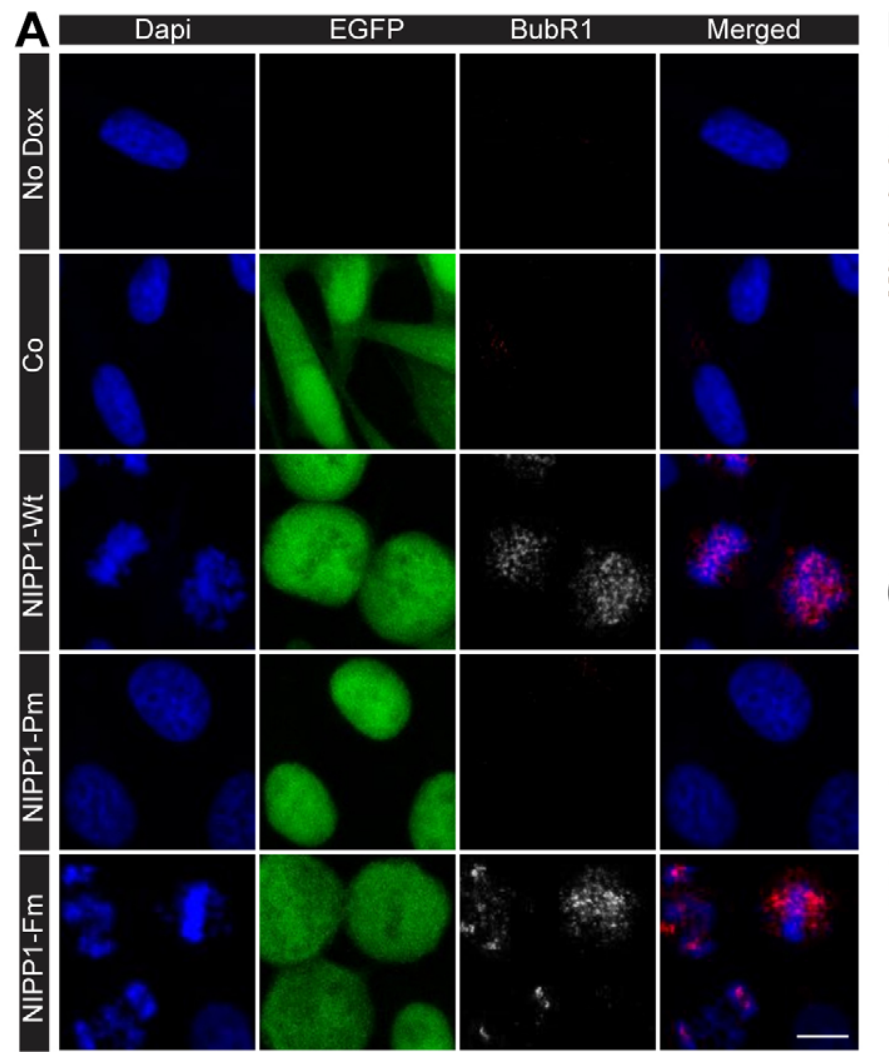

As hypothesized, the reduced cell survival in cells that expressed NIPP1-Fm was rescued by the mere addition of the Aurora inhibitor hesperadin (Fig. 6E).

\section{The selective inhibition of PP1 inhibits colony formation and tumor growth}

We have previously described stable HeLa Tet-off (HTO) cell lines that express Flag-tagged NIPP1-Wt or NIPP1-Pm in the absence of Dox (Fig. 7A) (Tanuma et al., 2008; Van Dessel et al., 2010). This enabled us to study the effect of the selective inhibition of PP1 on colony formation and tumor growth in the absence of an inducing agent. Consistent with our data obtained with the Flp-In T-REx cell lines (Fig. 2C), the expression of NIPP1-Wt in the HTO cell lines resulted in a gradual accumulation of dead cells, but this effect was not seen after the expression of NIPP1-Pm (Fig. 7B). The expression of NIPP1-Wt also hampered anchorage-dependent (Fig. 7C,D) and anchorage-independent colony formation (Fig. 7E,F). These effects were absent in HTO cells expressing NIPP1-Pm, demonstrating their dependency on PP1. In addition, solid-tumor formation following the subcutaneous injection of the HTO cells in nude mice was strongly reduced by the expression of NIPP1-Wt, but this effect was much smaller following the expression of NIPP1-Pm, as revealed by caliper measurements (Fig. 7G,H) and small-animal PET scan analysis (not illustrated). The tumor take of the control, NIPP1-Wt- and NIPP1-Pmexpressing cells was $100 \%, 88 \%$ and $94 \%$, respectively. At 30 days after injection, the average tumor size amounted to $1.13 \pm$ $0.19 \mathrm{~cm}^{3}$ (Co), $0.05 \pm 0.02 \mathrm{~cm}^{3}$ (NIPP1-Wt) and $0.36 \pm 0.08 \mathrm{~cm}^{3}$ (NIPP1-Pm) (mean \pm s.e.m, $n=16$, i.e. two flanks of eight mice). It was verified that the transgenes were expressed in the solid tumors formed after the injection of the NIPP1-Wt (Fig. 7I) and NIPP1-Pm (data not shown) cell lines. Moreover, the NIPP1-Wt-expressing cells showed increased expression levels of Kif18A, NuSAP and

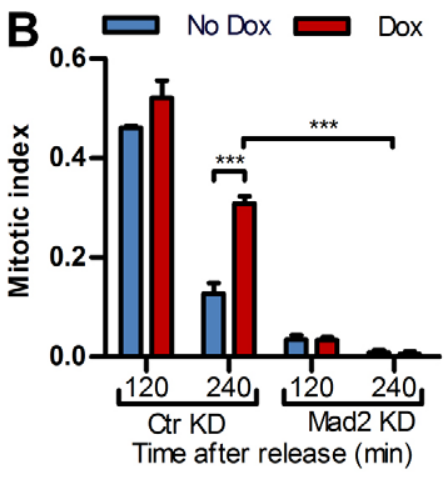

Fig. 4. The mitotic arrest induced by the overexpression of NIPP1 is associated with a prolonged SAC. (A) BubR1 stainings in the indicated cell lines, synchronized with a single thymidine arrest and released for $18 \mathrm{~h}$ Scale bar: $10 \mu \mathrm{m}$. No Dox refers to the control (Co) cell line. (B) After a contro (Ctr) or Mad2 knockdown (KD), noninduced and induced NIPP1-Wt cells were arrested at the G2/M transition with RO-3306 and released for 120 or $240 \mathrm{~min}$. The mitotic index

(percentage of rounded-up cells) was derived from cell rounding and represented as means \pm s.e.m. from two independent experiments $(n=1000$ cells). ${ }^{* *} P<0.001$ (Student's $t$-test). (C) The NIPP1-Wt and NIPP1-Fm cells, before and after induction, were synchronized with a single thymidine arrest, released for $5 \mathrm{~h}$ and then incubated with $0.33 \mu \mathrm{M}$ nocodazole. After 2 h, 100 nM hesperadin (Hesp) or $500 \mathrm{nM}$ reversine (Rev) was added and the SAC override time (time to cell flattening) was measured. Data are means \pm s.e.m. ( $n=50$ cells). ${ }^{* * *} P<0.001$ (Student's $t$-test)
TPX2 (Fig. 7I,J), which have previously been shown to be upregulated in mitotically arrested HeLa cells (Beck et al., 2011). Thus, the selective inhibition of PP1 impairs solid-tumor growth, which is associated with a mitotic arrest.

\section{DISCUSSION}

The main goal of this study was to delineate the contribution of PP1 to cell cycle progression in mammalian cancer cells. A knockdown approach was not an attractive option because of the redundancy between PP1 isoforms, which enables PIPs to form functional complexes with other PP1 isoforms once their preferred isozyme is removed (Gibbons et al., 2007; Kirchner et al., 2007; TrinkleMulcahy et al., 2006; Varmuza et al., 1999). In addition, none of the available small-molecule, cell-permeable inhibitors of PPP-type phosphatases is specific for PP1, making a chemical genetics approach unfeasible (De Munter et al., 2013; Gehringer, 2004; Kelker et al., 2009). Therefore, we aimed to inhibit the activity of PP1 using cell lines that inducibly express an inhibitory protein. A similar approach has recently been successfully used to explore the importance of PP2A for cell viability (Pores Fernando et al., 2014). Various protein inhibitors of PP1 have been identified but most of these are not suitable for studying global functions of PP1 in intact cells. Indeed, some PP1 inhibitors (e.g. Inhibitor-1 and CPI-17) are phosphorylation-dependent or only inhibit a subset of PP1 holoenzymes (Endo et al., 1996; Eto, 2009). Inhibitor-2, Inhibitor-3 and Sds22 have been biochemically identified as inhibitors of PP1, but genetic data from yeast indicate that they are actually positive regulators, possibly involved in the biogenesis of PP1 (Cheng and Chen, 2015; Eiteneuer et al., 2014; Heroes et al., 2015). In contrast, substantial biochemical and cell biological evidence indicates that full-length NIPP1 is a very specific and extremely potent inhibitor of PP1 (Beullens et al., 1992, 2000; O'Connell et al., 2012; Vulsteke et al., 1997). This applies to all 
A

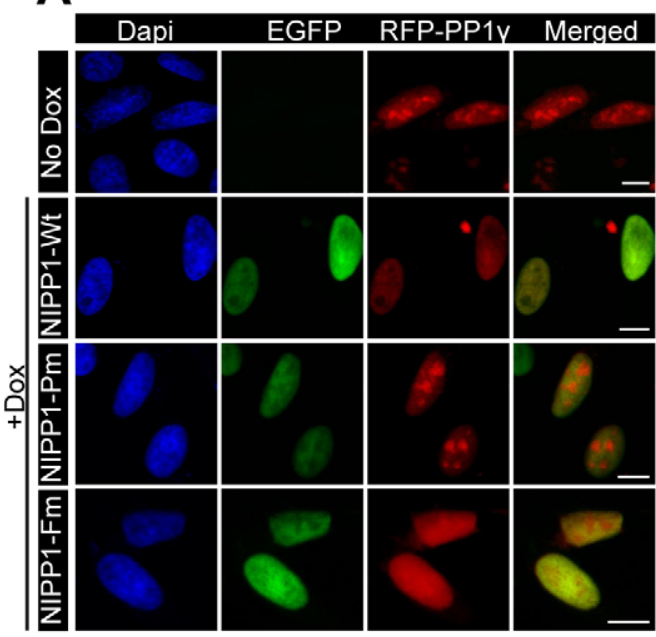

C

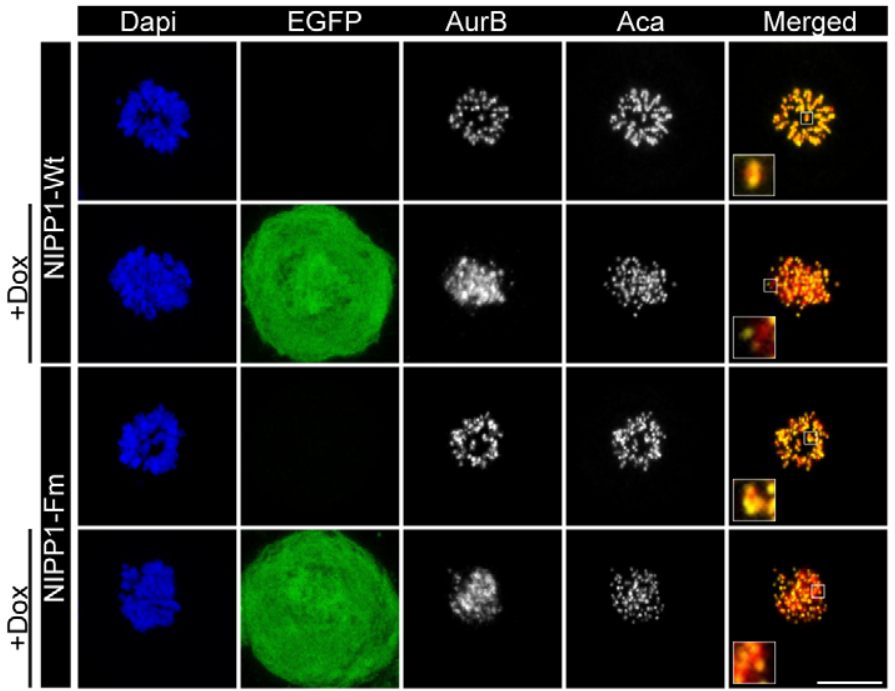

B

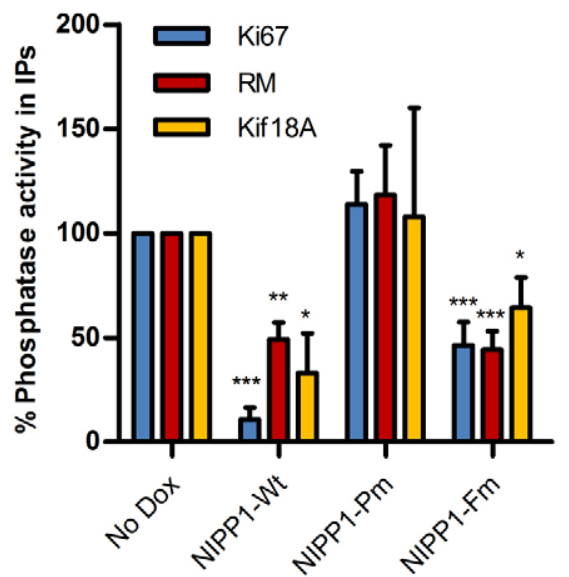

D

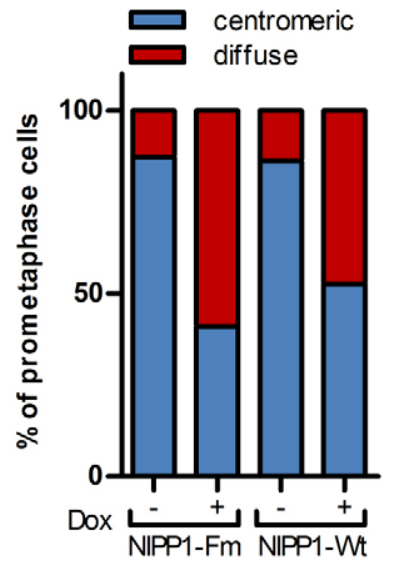

Fig. 5. Overexpression of NIPP1 disrupts PP1-PIP interactions.

(A) Localization of transiently expressed RFP-PP1 $\gamma$ before and after the induction of the indicated EGFP-NIPP1

transgenes. Scale bars: $10 \mu \mathrm{m}$. No Dox refers to the NIPP1-Wt cell line.

(B) Phosphorylase phosphatase activity in immunoprecipitates of Ki67, RepoMan (RM) and Kif18A from STLC-arrested cells before and after induction of the indicated transgenes. Results are represented as percentages of the corresponding non-induced condition and corrected for the amount of the immunoprecipitated proteins. Data are means \pm s.e.m. from four independent experiments. ${ }^{*} P<0.05$; ${ }^{* *} P<0.01$;

${ }^{* * *} P<0.001$ (Student's $t$-test). (C) Aurora $B$ stainings in the indicated cell lines, synchronized with a single thymidine arrest and nocodazole for $16 \mathrm{~h}$. Aca served as a centromere marker. Scale bar: $10 \mu \mathrm{m}$. (D) Quantification of Aurora B localization ( $n=50$ cells) tested protein substrates of PP1, except for phosphoproteins that are recruited through the FHA domain and probably represent the natural substrates of the PP1-NIPP1 holoenzyme. Hence, NIPP1 with a non-functional FHA domain (NIPP1-Fm) can be used as a general and specific inhibitor of PP1. Accordingly, we have found that both NIPP1-Wt and NIPP1-Fm titrate PP1 away from other PP1 holoenzymes (Fig. 5; Fig. S4A,B,D) and that the retained PP1 is inactive towards an exogenous PP1 substrate (Fig. S1C).

A very mild overexpression of NIPP1 in stable HeLa cell lines $(<10 \%)$, due to promoter leakage from the non-induced transgenes, causes the expression of mesenchymal genes (Van Dessel et al., 2015). However, this low level of overexpression had no effect on the progression through mitosis (Fig. 2). In contrast, the induced overexpression of NIPP1-Wt or NIPP1-Fm to levels that are severalfold higher than that of endogenous NIPP1 caused a mitotic arrest in a large majority of cells. This effect was not seen with a PP1-binding mutant of NIPP1 (NIPP1-Pm) and could be partially rescued by the overexpression of PP1 $\gamma$ (Fig. 6A-D; Fig. S4E,F), which represents strong independent evidence that this phenotype stems from the binding and inhibition of PP1. Interestingly, the mitotic-arrest phenotype could also be rescued by the inhibition of Aurora B kinase (Fig. 6E), consistent with the notion that PP1 balances or reverses signaling by Aurora kinases in mitosis, by directly inactivating the kinases themselves and/or by dephosphorylating their substrates (Emanuele et al., 2008; Lesage et al., 2011; Liu et al., 2010). In general, our data demonstrate that PP1 is essential for progression through $\mathrm{M}$ phase in HeLa cells, which is in accordance with previous findings for fungi and Drosophila (Axton et al., 1990; Chen et al., 2007; Doonan and Morris, 1989; Hisamoto et al., 1994). It is possible that major functions of PP1 in other phases of the cell cycle have been masked in our experiments because NIPP1 is a nuclear protein and might not have been able to titrate PP1 away from cytoplasmic PP1 holoenzymes that are essential in interphase.

The prometaphase arrest that was induced by the expression of NIPP1-Wt or NIPP1-Fm was associated with major spindle-assembly and chromosome-congression defects, and a prolonged SAC (Figs 3 and 4). In addition, SAC inactivation was hampered by the inhibition of PP1. Many NIPP1-Wt- or NIPP1-Fm-expressing cells eventually died in mitosis through apoptosis (Fig. 2B,C), also known as 'mitotic catastrophe' (Castedo et al., 2004). Other cells exited mitosis and returned to interphase without undergoing cytokinesis, a process known as 'slippage' (Gascoigne and Taylor, 2008; Topham and Taylor, 2013). Slippage occurs because the Cdk1 regulator cyclin B1 

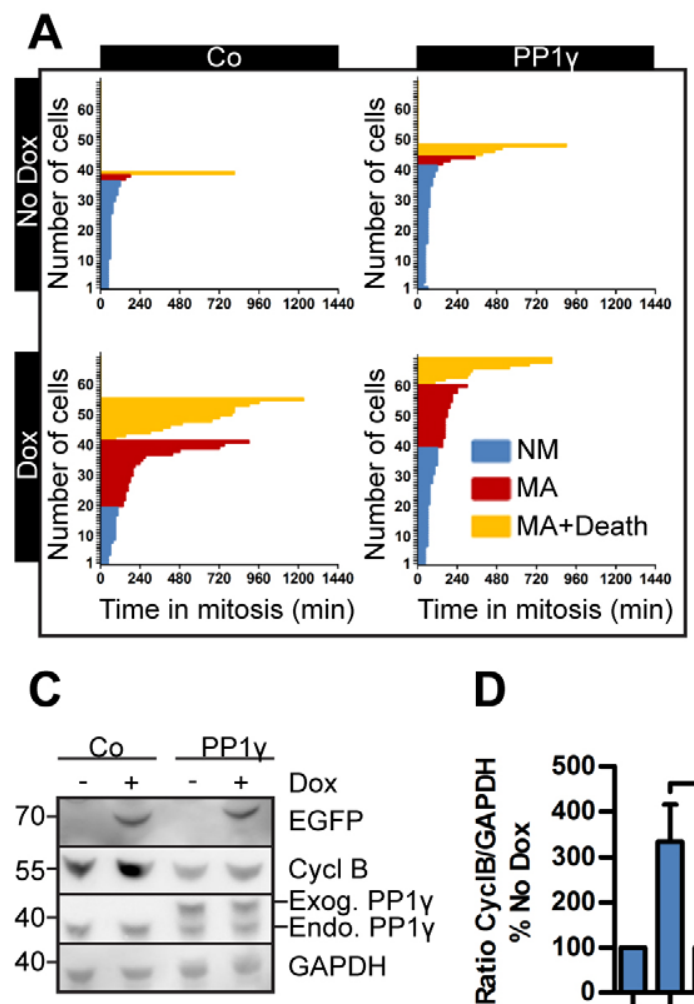

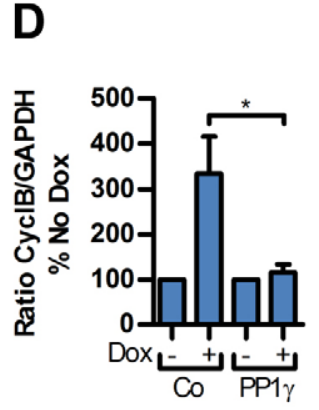

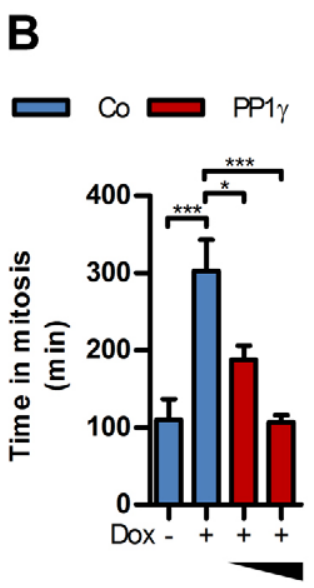

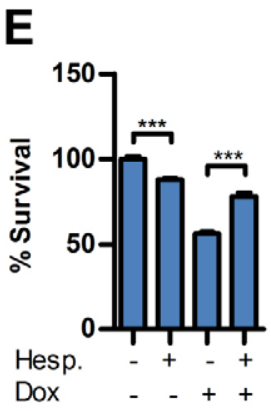

Fig. 6. The NIPP1-induced mitotic-arrest phenotype stems from the inhibition of PP1. (A) Mitotic cell fate under NIPP1-Fm induced and non-induced conditions, and the transient co-expression of RFP (Co) or RFP-PP1 $\gamma$. At 1 day after RFP-PP $1 \gamma$ transfection, the cells were arrested with $2 \mathrm{mM}$ thymidine for $24 \mathrm{~h}$. Dox was added $8 \mathrm{~h}$ after thymidine. Time-lapse imaging was started $8 \mathrm{~h}$ after the removal of thymidine. Cell fates were defined as in

Fig. 2B,C. (B) Duration of mitosis in the same conditions. A distinction was made between cells that expressed low and high levels of RFP-PP1 (triangle under the graph), as deduced from RFP color intensity. Data are presented as mean \pm s.e.m. from 50 cells. ${ }^{*} P<0.05 ;{ }^{* * *} P<0.001$ (Student's t-test). (C) NIPP1-Fm cells (with or without Dox) were transfected for the transient expression of Flag (Co) or Flag-PP $1 \gamma$. The cells were arrested with a single thymidine block and released for $18 \mathrm{~h}$. Dox was added together with thymidine. The figure shows immunoblots of EGFP, Cyclin $\mathrm{B}(\mathrm{CyclB})$ and PP1 $\gamma$ in cell lysates. GAPDH served as a loading control. Endo, endogenous; Exo, exogenous. (D) Cyclin B:GAPDH ratios for the same conditions as $C$. The data represent means \pm s.e.m. $(n=4)$. ${ }^{*} P<0.05$ (Student's $t$-test). (E) Rescue of reduced cell survival after the expression of NIPP1-Fm by the addition of the Aurora inhibitor hesperadin. Cell survival was calculated from sulforhodamine B assays after the induction of NIPP1-Fm. The cells were treated with Dox $(0.5 \mathrm{ng} / \mathrm{ml})$, in the absence or presence of $143 \mathrm{nM}$ of hesperadin. Data are presented as means \pm s.e.m. $(n=3) .{ }^{* *} P<0.001$ (Student's $t$-test). is slowly degraded, even when the SAC is active, which eventually causes the Cdk1 activity to drop below the threshold level that is needed for maintaining the mitotic state. The balance between mitotic catastrophe and slippage is dependent on the cell type but also shows considerable cell-to-cell variation (Gascoigne and Taylor, 2008; Topham and Taylor, 2013), explaining why the outcome of the expression of NIPP1-Wt or NIPP1-Fm was not the same in all cells. In any case, the severity and complexity of the observed mitotic-arrest phenotype suggests that PP1 has multiple essential substrates in mitosis, which agrees with the identification of multiple PIPs that mediate the targeting of PP1 to the centrosomes, spindle and chromosomes (Bollen et al., 2009; Wurzenberger and Gerlich, 2011). We speculate that HeLa cell lines that inducibly express NIPP1-Fm can be used in rescue experiments to identify the PIPs that are important for spindle formation, microtubule dynamics, chromosome congression and SAC silencing.

The mitotic-arrest phenotypes were generally somewhat stronger for NIPP1-Wt than for NIPP1-Fm. Indeed, the expression of NIPP1Wt caused more severe chromosome congression defects, as indicated by an increased number of misaligned chromosomes (Fig. 3F,G). It also caused a spindle-pole focusing defect, which was not seen after the expression of NIPP1-Fm. In addition, NIPP1-Wtexpressing cells showed a higher incidence of mitotic catastrophe (Fig. 2B,C). Taken together, these results hint at a contribution of the FHA domain to the phenotype of overexpression of NIPP1-Wt. Importantly, there was no mitotic phenotype after the expression of NIPP1 that was mutated in both its FHA domain and RVxF-type PP1-binding site, indicating that the contribution of the FHA domain is PP1-dependent and cannot be explained by the mere titration of FHA ligands from other protein complexes. Given that NIPP1 enables the dephosphorylation of FHA ligands by associated PP1 in a cellular context, we speculate that the stronger phenotype associated with the expression of NIPP1-Wt is due to the recruitment and subsequent dephosphorylation of FHA ligand(s). It is known that at least some NIPP1 FHA ligands are dephosphorylated at the end of mitosis (Badouel et al., 2010; Boudrez et al., 2000, 2002; Dulla et al., 2010; Minnebo et al., 2013), but it remains to be investigated whether the overexpression of NIPP1 affects the dephosphorylation of its FHA ligands during mitosis and whether this contributes to the mitotic arrest.

Finally, we have demonstrated that the overexpression of NIPP1 also hampers anchorage-dependent and -independent colony formation and tumor growth in xenograft assays in a PP1-dependent manner (Fig. 7). These data suggest that PP1 is a potential target for the development of novel cancer therapies. We envisage that such therapies will not be based on inhibitors of the catalytic subunit, which are likely to be toxic, unless they can be specifically targeted to cancer cells (De Munter et al., 2013). At present there appears to be a better therapeutic potential for molecules that interfere with the assembly or substrate recruitment of key mitotic PP1 holoenzymes, in particular those that are upregulated in cancer cells.

\section{MATERIALS AND METHODS}

\section{Materials}

Anti-EGFP, anti-PP1 $\gamma$ and sulforhodamine B were purchased from Santa Cruz Biotechnology. Anti- $\alpha$-tubulin and anti-RepoMan antibodies, nocodazole, mineral oil and doxycycline hyclate were obtained from Sigma-Aldrich. Anti-GAPDH and anti-cleaved caspase 3 antibodies were purchased from Cell Signaling Technology, and anti-BubR1 and antiKif18A antibodies from Bethyl laboratories. The anti-NIPP1 and anti-PP1 antibodies were made in-house, as previously described (Van Dessel et al., 2010). Anti-Sap155, anti-cyclin B1, anti- $\gamma-\mathrm{H} 2 \mathrm{Ax}$, anti-Aurora B, anti-Aca and anti-Flag antibodies were purchased from MBL International, BD Pharmingen, Millipore, BD Transduction Laboratories, ImmunoVision (Springdale, AR) and Stratagene, respectively. Anti-Ki67 and anti-centrobin 
A
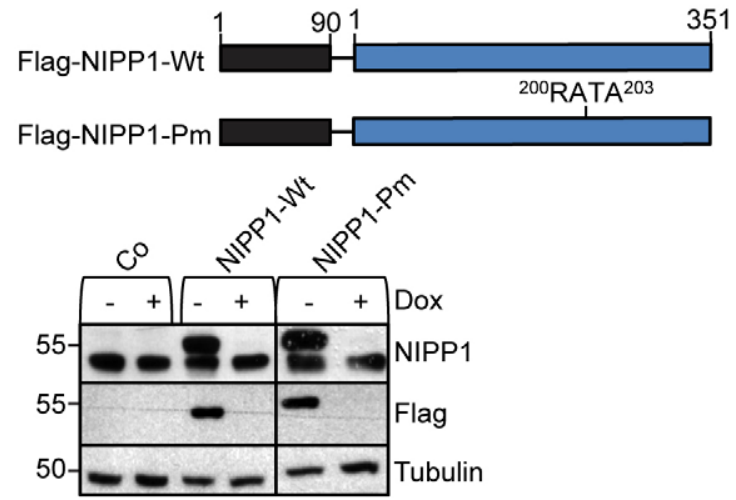

C

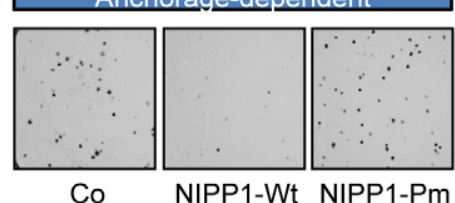

E

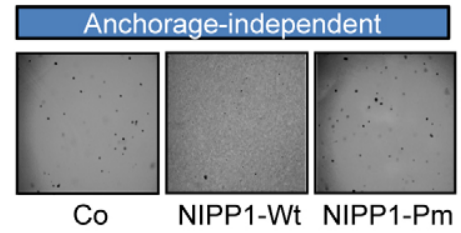

G

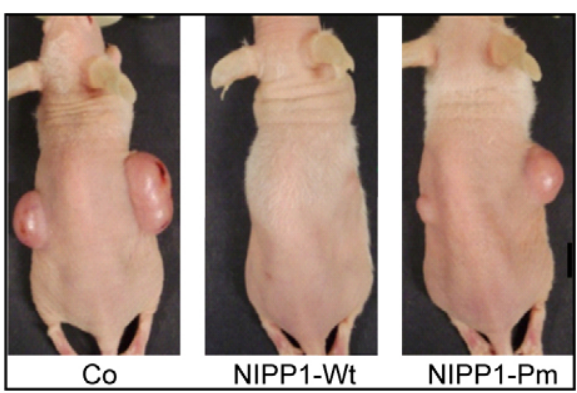

I
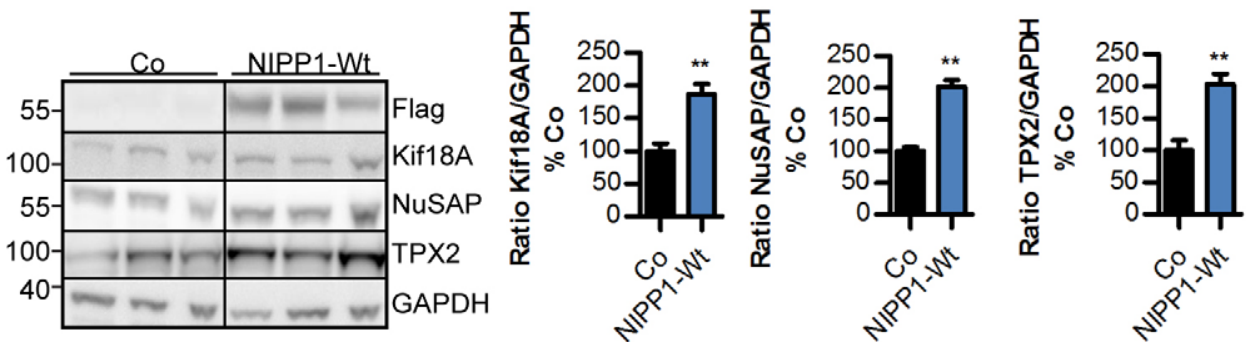

Fig. 7. The selective inhibition of PP1 in HeLa cells hampers colony formation and tumor growth in xenograft assays. (A) Schematic representation of the Flagtagged NIPP1 fusions used for generating stable HeLa Tet-Off (HTO) cell lines. The immunoblots underneath show the expression of the Flag-NIPP1 fusions and endogenous NIPP1 in the absence and presence of Dox. Tubulin served as loading control. (B) Cell death, as measured by

Trypan Blue stainings, after the expression of NIPP1-Wt or NIPP1-Pm for 24-96 h. The parental cell line was used as control (Co). The data represents means \pm s.e.m. $(n=3)$. ${ }^{*} P<0.05 ;{ }^{* *} P<0.001$ (Student's $t$-test).

(C) Anchorage-dependent growth of the cell lines in the absence of Dox.

(D) Quantification of data from experiments as shown in panel $\mathrm{C}$. The bars represent means \pm s.e.m. $(n=3)$. * $P<0.05$ (Student's $t$-test). (E) Anchorage-independent growth of the cell lines in the absence of Dox. (F) Quantification of data from experiments as shown in panel $\mathrm{E}$. The bars represent means \pm s.e.m. $(n=3)$. * $P<0.05$ (Student's t-test). (G) The indicated HTO cells were subcutaneously injected into both flanks of athymic mice. Parental cells (Co) were used as controls. The figure shows representative pictures of the mice 4 weeks after injection. (H) Caliper-measured tumor volumes at the indicated times after injection of the cells.

The data represent means \pm s.e.m. $(n=16$, i.e. two flanks of 8 mice). ${ }^{*} P<0.05$

(Student's $t$-test). (I) Representative immunoblots of tumor lysates. The blots show the expression of Flag-NIPP1-Wt and the mitotic markers Kif18A, NuSAP and TPX2. GAPDH served as loading control. (J) Quantification of data from experiments as shown in panel I. The bars represent means \pm s.e.m. $(n=5-8) .{ }^{* *} P<0.01$

(Student's $t$-test) antibodies were purchased from Abcam. Anti-NuSAP antibodies were obtained from ProteinTech (Manchester, UK) and anti-TPX2 antibodies from Novus Biologicals (Abingdon, UK). Secondary HRP-conjugated antibodies and anti-Ki67 antibody were purchased from Dako (Heverlee, $\mathrm{BE}$ ) and secondary Alexa-Fluor-555- and 633-conjugated antibodies were from Invitrogen. S-Trityl-L-Cysteine (STLC), hesperadin, thymidine, reversine and RO-3306 were purchased from Calbiochem, Selleckchem (Munich, Germany), Acros organics (Geel, Belgium), Cayman Chemical and Tocris (Bristol, UK), respectively.

\section{Cell culture and imaging}

Hela Tet-off cell lines expressing Flag-tagged NIPP1 variants in the absence of doxycycline (Dox) and Flip-In T-REx cell lines expressing EGFP or EGFP-tagged NIPP1 variants in the presence of Dox were obtained as described previously (Tanuma et al., 2008; Van Dessel et al., 2015). Transfections were carried out using a commercial kit (Jet-Prime, Polyplus), according to the manufacturer's instructions. The used Mad2 small interfering RNA (siRNA) has been described previously (Maldonado and Kapoor, 2011). For immunofluorescence studies, cells grown on coverslips 
were fixed with $4 \%$ formaldehyde in Phem buffer ( $60 \mathrm{mM}$ PIPES at $\mathrm{pH} 7$, $25 \mathrm{mM}$ Hepes $\mathrm{pH}$ 7, $10 \mathrm{mM}$ EGTA and $2 \mathrm{mM} \mathrm{MgCl}_{2}$ ), permeabilized with $0.5 \%$ Triton X-100 and blocked with $3 \%$ BSA in PBS. After incubation with primary and secondary antibodies, and DNA staining with DAPI, the coverslips were mounted in Mowiol onto microscope slides. For some experiments, a pre-extraction was performed. In that case, cells were incubated before fixation for 4 min at $4^{\circ} \mathrm{C}$ with CSK buffer $(10 \mathrm{mM}$ PIPES at $\mathrm{pH} 6.8,300 \mathrm{mM}$ sucrose, $100 \mathrm{mM} \mathrm{NaCl}$ and $3 \mathrm{mM} \mathrm{MgCl}_{2}$ ), supplemented with $0.2 \%$ Triton X-100. Confocal images were acquired with a Leica TCS SPE laser scanning confocal system mounted on a Leica DMI 4000B microscope and equipped with a Leica ACS APO $40 \times$ or $63 \times 1.30$ NA oil objective.

For live-cell imaging, cells were grown in chambered coverglass fourwell plates from Thermo Scientific. For DIC imaging, cells were synchronized with a double thymidine arrest $(2 \mathrm{mM}$ thymidine for $18 \mathrm{~h}$, $9 \mathrm{~h}$ release, $2 \mathrm{mM}$ thymidine for $16 \mathrm{~h}$ ). Dox was added together with induction of the second thymidine block. After release from this arrest the cells were imaged for $60 \mathrm{~h}$ with a Leica TCS SPE laser scanning microscope using a $20 \times$ magnification objective. Mineral oil was added to prevent evaporation of the medium. For H2B imaging, cells were transfected with Cherry-H2B, synchronized with a single thymidine arrest $(2 \mathrm{mM}$ thymidine for $18-20 \mathrm{~h}$ ) and after release imaged for $20 \mathrm{~h}$ using a $40 \times$ magnification objective. The SAC override assay has been described previously (Santaguida et al., 2011). The microscope was equipped with a liveimaging chamber ensuring $37^{\circ} \mathrm{C}$ and $5 \% \mathrm{CO}_{2}$. Images were taken every $10 \mathrm{~min}$ (H2B and SAC override assays) or $15 \mathrm{~min}$ (DIC time-lapse imaging). Images and movies were processed with the ImageJ software (National Institutes of Health). For quantifying the amount of RFP-PP1 overexpression (Fig. 6B), $z$-stack scans were performed with wide-field microscopy (12 sections with $4-\mu \mathrm{m}$ intervals), before live-cell imaging was started. After processing the signals with the ImageJ software using the 'sum slices' feature of z-project, a circular region with fixed diameter was centered on randomly chosen cells and raw integrated intensities were measured. After subtraction of the background signal, two thresholds for PP1 expression were determined. Cells harboring RFP intensities below 350,000 were classified as 'low overexpressing', above that value, cells were classified as 'high overexpressing'.

Cell viability in HTO cells (Fig. 7B) was measured with Trypan Blue. For this purpose, HTO cells were seeded in a 24 -well plate (3500 cells/well). After 24, 48 and $96 \mathrm{~h}$, Trypan Blue was added and the percentage of colored cells was taken as a measure of cell death. Cell survival in Flp-In T-REx cells (Figs 1C and 6E) was derived from sulforhodamine B colorimetric assays (Voigt, 2005). For these experiments cells were treated with $143 \mathrm{nM}$ hesperadin or DMSO, and the indicated amounts of Dox for $48 \mathrm{~h}$. After fixation and staining with $0.4 \%$ sulforhodamine B the absorbance was measured at $550 \mathrm{~nm}$.

\section{FACS analysis}

FACS analysis was performed as described previously (Kig et al., 2013). Briefly, asynchronous growing cells were induced or non-induced for $48 \mathrm{~h}$. After fixation in $70 \%$ ethanol, cells were stained with $50 \mu \mathrm{g} / \mathrm{ml}$ propidium iodide (Sigma) and the DNA content was analyzed by cytometric analysis (Attune Acoustic Focusing Cytometer), using the Attune FACS software. To examine the variability of EGFP expression of the different transgenes (Fig. S1A), cells were induced or non-induced for $24 \mathrm{~h}$. Following fixation with $70 \%$ ethanol for $10 \mathrm{~min}$ at room temperature, EGFP-expressing cells were quantified with the Attune cytometer, using the Attune FACS software.

\section{Immunoprecipitation}

Immunoblotting and EGFP-trapping were performed as described previously (Kig et al., 2013; Van Dessel et al., 2010). For the immunoprecipitation of endogenous Ki67, RepoMan and Kif18A, cells were first synchronized with a single thymidine arrest, released for $5 \mathrm{~h}$ and incubated for $16 \mathrm{~h}$ with $7.5 \mu \mathrm{M}$ S-Trityl-L-cysteine (STLC). Cells were then lysed in RIPA lysis buffer (50 mM Tris- $\mathrm{HCl} \mathrm{pH} \mathrm{8,} 150 \mathrm{mM} \mathrm{NaCl}, 1 \mathrm{mM}$ EDTA, $0.5 \%$ sodium deoxycholate, $1 \%$ Triton X-100 and $0.1 \%$ SDS). After centrifugation $(10 \mathrm{~min}$ at $3000 \mathrm{~g})$, the supernatants were used for the immunoprecipitation with the appropriate antibodies and protein-A-
Sepharose (GE Healthcare). The immunoprecipitates were washed once with TBS complemented with $0.1 \mathrm{M} \mathrm{LiCl}$, and three times with TBS containing $0.1 \% \mathrm{NP}-40$. Afterwards, precipitates were assayed for the presence of PP1 by measuring the glycogen phosphorylase phosphatase activity (Beullens et al., 1992).

\section{Colony formation and xenograft assays}

For anchorage-dependent growth, 500 HTO cells were seeded in 10-cm plates. After 2 weeks, the colonies were fixed, stained with Crystal Violet, photographed and counted with a ColCount (Oxford Optronix, Oxford, UK). For anchorage-independent growth, 40,000 HTO cells were first mixed with $2 \mathrm{ml}$ of culture medium containing $0.35 \%$ agarose and plated on top of a basal layer of medium containing $0.6 \%$ agarose in a 6 -well plate. After 1 week, a fresh layer of culture medium containing $0.35 \%$ agarose was added. After a further 2 weeks, pictures were taken.

HTO cells were cultured for 3 days in the absence of Dox. Subsequently, $3 \times 10^{6}$ cells were subcutaneously injected into both flanks of eight athymic mice. Tumor size was measured at the indicated time points with a caliper. Additionally, after 4 weeks the tumors of the three mice closest to the median of each group were visualized with small animal PET (Focus 220 microPET; Concorde-CTI/Siemens) and analyzed as previously described (Deroose et al., 2007). All animal experiments were performed according to approved guidelines.

\section{Statistics}

The statistical significance between control and experimental groups was calculated using paired or unpaired Student's $t$-tests and is denoted as $* * * P<0.001 ; * * P<0.01 ; * P<0.05$.

\section{Acknowledgements}

We thank Annemie Hoogmartens and Fabienne Withof for providing technical assistance.

\section{Competing interests}

The authors declare no competing or financial interests.

\section{Author contributions}

C.W., S.D.M. and N.V.D. designed and performed the experiments, and analyzed the data. E.H. and S.B. helped with the xenograft assays. B.L. helped with the design of experiments and live-cell imaging. M.Bo., A.V.E. and M.Be. supervised the design and execution of the experiments, and M.Bo. coordinated the project. M.Bo. and C.W. wrote the manuscript.

\section{Funding}

This work was supported by the Fund for Scientific Research-Flanders [grant numbers G.0473.12, G.0482.12]; and Flemish Concerted Research Action [grant number GOA 15/016].

\section{Supplementary information}

Supplementary information available online at

http://jcs.biologists.org/lookup/suppl/doi:10.1242/jcs.175588/-/DC1

\section{References}

Axton, J. M., Dombrádi, V., Cohen, P. T. W. and Glover, D. M. (1990). One of the protein phosphatase 1 isoenzymes in Drosophila is essential for mitosis. Cell 63, 33-46.

Badouel, C., Chartrain, I., Blot, J. and Tassan, J.-P. (2010). Maternal embryonic leucine zipper kinase is stabilized in mitosis by phosphorylation and is partially degraded upon mitotic exit. Exp. Cell Res. 316, 2166-2173.

Beck, M., Schmidt, A., Malmstroem, J., Claassen, M., Ori, A., Szymborska, A., Herzog, F., Rinner, O., Ellenberg, J. and Aebersold, R. (2011). The quantitative proteome of a human cell line. Mol. Syst. Biol. 7, 1-8.

Beullens, M., Van Eynde, A. and Stalmans, W. (1992). The isolation of novel inhibitory polypeptides of protein phosphatase 1 from bovine thymus nuclei. J. Biol. Chem. 267, 16538-16544.

Beullens, M., Stalmans, W. and Bollen, M. (1998). The biochemical identification and characterization of new species of protein phosphatase 1. In Methods in Molecular Biology (ed. J. W. Ludlow), pp. 145-155. Totowa, NJ: Humana Press, Inc. Beullens, M., Vulsteke, V., Van Eynde, A., Jagiello, I., Stalmans, W. and Bollen, M. (2000). The C-terminus of NIPP1 (nuclear inhibitor of protein phosphatase-1) contains a novel binding site for protein phosphatase- 1 that is controlled by tyrosine phosphorylation and RNA binding. Biochem. J. 352, 651-658. 
Bollen, M., Gerlich, D. W. and Lesage, B. (2009). Mitotic phosphatases: from entry guards to exit guides. Trends Cell Biol. 19, 531-541.

Booth, D. G., Takagi, M., Sanchez-Pulido, L., Petfalski, E., Vargiu, G. Samejima, K., Imamoto, N., Ponting, C. P., Tollervey, D., Earnshaw, W. C. et al. (2014). Ki-67 is a PP1-interacting protein that organises the mitotic chromosome periphery. Elife 2014, e01641.

Boudrez, A., Beullens, M., Groenen, P., Van Eynde, A., Vulsteke, V., Jagiello, I., Murray, M., Krainer, A. R., Stalmans, W. and Bollen, M. (2000). NIPP1mediated interaction of protein phosphatase-1 with CDC5L, a regulator of premRNA splicing and mitotic entry. J. Biol. Chem. 275, 25411-25417.

Boudrez, A., Beullens, M., Waelkens, E., Stalmans, W. and Bollen, M. (2002) Phosphorylation-dependent interaction between the splicing factors SAP155 and NIPP1. J. Biol. Chem. 277, 31834-31841.

Castedo, M., Perfettini, J.-L., Roumier, T., Andreau, K., Medema, R. and Kroemer, G. (2004). Cell death by mitotic catastrophe: a molecular definition. Oncogene 23, 2825-2837.

Chen, F., Archambault, V., Kar, A., Lio', P., D'Avino, P. P., Sinka, R., Lilley, K., Laue, E. D., Deak, P., Capalbo, L. et al. (2007). Multiple protein phosphatases are required for mitosis in Drosophila. Curr. Biol. 17, 293-303.

Cheng, Y.-L. and Chen, R.-H. (2015). Assembly and quality control of the protein phosphatase 1 holoenzyme involves the Cdc48-Shp1 chaperone. J. Cell Sci. 128 1180-1192.

Cheng, A., Dean, N. M. and Honkanen, R. E. (2000). Serine/threonine protein phosphatase type 1gamma1 is required for the completion of cytokinesis in human A549 lung carcinoma cells. J. Biol. Chem. 275, 1846-1854.

De Munter, S., Köhn, M. and Bollen, M. (2013). Challenges and opportunities in the development of protein phosphatase-directed therapeutics. ACS Chem. Biol. 8, 36-45

Deroose, C., De, A., Loening, A., Chow, P., Ray, P., Chatziioannou, A. and Gambhir, S. (2007). Multimodality imaging of tumor xenografts and metastases in mice with combined small-animal PET, small-animal CT, and bioluminescence imaging. J. Nucl. Med. 48, 295-303.

Doonan, J. H. and Morris, N. R. (1989). The bimG gene of Aspergillus nidulans, required for completion of anaphase, encodes a homolog of mammalian phosphoprotein phosphatase 1. Cell 57, 987-996.

Dulla, K., Daub, H., Hornberger, R., Nigg, E. A. and Körner, R. (2010) Quantitative site-specific phosphorylation dynamics of human protein kinases during mitotic progression. Mol. Cell. Proteomics 9, 1167-1181.

Eiteneuer, A., Seiler, J., Weith, M., Beullens, M., Lesage, B., Krenn, V., Musacchio, A., Bollen, M. and Meyer, H. (2014). Inhibitor-3 ensures bipola mitotic spindle attachment by limiting association of SDS22 with kinetochorebound protein phosphatase-1. EMBO J. 33, 2704-2720.

Emanuele, M. J., Lan, W., Jwa, M., Miller, S. A., Chan, C. S. M. and Stukenberg, P. T. (2008). Aurora B kinase and protein phosphatase 1 have opposing roles in modulating kinetochore assembly. J. Cell Biol. 181, 241-254.

Endo, S., Zhou, X., Connor, J., Wang, B. and Shenolikar, S. (1996). Multiple structural elements define the specificity of recombinant human inhibitor-1 as a protein phosphatase-1 inhibitor. Biochemistry 35, 5220-5228.

Espert, A., Uluocak, P., Bastos, R. N., Mangat, D., Graab, P. and Gruneberg, U. (2014). PP2A-B56 opposes Mps1 phosphorylation of Knl1 and thereby promotes spindle assembly checkpoint silencing. J. Cell Biol. 206, 833-842.

Eto, M. (2009). Regulation of cellular protein phosphatase-1 (PP1) by phosphorylation of the CPI-17 family, C-kinase-activated PP1 Inhibitors. J. Biol. Chem. 284, 35273-35277.

Fernandez, A., Brautigan, D. L. and Lamb, N. J. (1992). Protein phosphatase type 1 in mammalian cell mitosis: chromosomal localization and involvement in mitotic exit. J. Cell Biol. 116, 1421-1430.

Gascoigne, K. E. and Taylor, S. S. (2008). Cancer cells display profound intra- and interline variation following prolonged exposure to antimitotic drugs. Cancer Cell 14, 111-122

Gehringer, M. M. (2004). Microcystin-LR and okadaic acid-induced cellular effects: a dualistic response. FEBS Lett. 557, 1-8.

Gibbons, J. A., Kozubowski, L., Tatchell, K. and Shenolikar, S. (2007). Expression of human protein phosphatase-1 in Saccharomyces cerevisiae highlights the role of phosphatase isoforms in regulating eukaryotic functions. J. Biol. Chem. 282, 21838-21847.

Häfner, J., Mayr, M. I., Möckel, M. M. and Mayer, T. U. (2014). Pre-anaphase chromosome oscillations are regulated by the antagonistic activities of Cdk1 and PP1 on Kif18A. Nat. Commun. 5, 4397.

Heroes, E., Lesage, B., Görnemann, J., Beullens, M., Van Meervelt, L. and Bollen, M. (2013). The PP1 binding code: a molecular-lego strategy that governs specificity. FEBS J. 280, 584-595.

Heroes, E., Rip, J., Beullens, M., Van Meervelt, L., De Gendt, S. and Bollen, M. (2015). Metals in the active site of native protein phosphatase-1. J. Inorg. Biochem. 149, 1-5

Hiraga, S.-I., Alvino, G. M., Chang, F., Lian, H.-Y., Sridhar, A., Kubota, T. Brewer, B. J., Weinreich, M., Raghuraman, M. K. and Donaldson, A. D. (2014) Rif1 controls DNA replication by directing Protein Phosphatase 1 to reverse Cdc7mediated phosphorylation of the MCM complex. Genes Dev. 28, 372-383.
Hisamoto, N., Sugimoto, K. and Matsumoto, K. (1994). The Glc7 type 1 protein phosphatase of Saccharomyces cerevisiae is required for cell cycle progression in G2/M. Mol. Cell. Biol. 14, 3158-3165.

Jagiello, I., Van Eynde, A., Vulsteke, V., Beullens, M., Boudrez, A., Keppens, S. Stalmans, W. and Bollen, M. (2000). Nuclear and subnuclear targeting sequences of the protein phosphatase-1 regulator NIPP1. J. Cell Sci. 113, 3761-3768.

Kelker, M. S., Page, R. and Peti, W. (2009). Crystal structures of protein phosphatase-1 bound to Nodularin-R and Tautomycin: a novel scaffold fo structure-based drug design of serine/threonine phosphatase inhibitors. J. Mol. Biol. 385, 11-21.

Kig, C., Beullens, M., Beke, L., Van Eynde, A., Linders, J. T., Brehmer, D. and Bollen, M. (2013). Maternal embryonic leucine zipper kinase (MELK) reduces replication stress in glioblastoma cells. J. Biol. Chem. 288, 24200-24212.

Kim, Y., Holland, A. J., Lan, W. and Cleveland, D. W. (2010). Aurora kinases and protein phosphatase 1 mediate chromosome congression through regulation of CENP-E. Cell 142, 444-455

Kirchner, J., Gross, S., Bennett, D. and Alphey, L. (2007). Essential, overlapping and redundant roles of the Drosophila protein phosphatase 1alpha and 1beta genes. Genetics 176, 273-281.

Lesage, B., Qian, J. and Bollen, M. (2011). Spindle checkpoint silencing: PP1 tips the balance. Curr. Biol. 21, R898-R903.

Liu, D., Vleugel, M., Backer, C. B., Hori, T., Fukagawa, T., Cheeseman, I. M. and Lampson, M. A. (2010). Regulated targeting of protein phosphatase 1 to the outer kinetochore by KNL1 opposes Aurora B kinase. J. Cell Biol. 188, 809-820.

London, N., Ceto, S., Ranish, J. A. and Biggins, S. (2012). Phosphoregulation of Spc105 by Mps1 and PP1 regulates Bub1 localization to kinetochores. Curr. Biol. 22, 900-906

Ludlow, J. W., Glendening, C. L., Livingston, D. M. and DeCarprio, J. A. (1993) Specific enzymatic dephosphorylation of the retinoblastoma protein. Mol. Cell. Biol. 13, 367-372.

Maldonado, M. and Kapoor, T. M. (2011). Constitutive Mad1 targeting to kinetochores uncouples checkpoint signalling from chromosome biorientation. Nat. Cell Biol. 13, 475-482.

Margolis, S. S., Perry, J. A., Weitzel, D. H., Freel, C. D., Yoshida, M., Haystead T. A. and Kornbluth, S. (2006). A role for PP1 in the Cdc2/Cyclin B-mediated positive feedback activation of Cdc25. Mol. Biol. Cell 17, 1779-1789.

Meadows, J. C., Shepperd, L. A., Vanoosthuyse, V., Lancaster, T. C., Sochaj, A. M., Buttrick, G. J., Hardwick, K. G. and Millar, J. B. A. (2011). Spindle checkpoint silencing requires association of PP1 to both Spc7 and kinesin-8 motors. Dev. Cell 20, 739-750.

Minnebo, N., Görnemann, J., O'Connell, N., Van Dessel, N., Derua, R., Vermunt M. W., Page, R., Beullens, M., Peti, W., Van Eynde, A. et al. (2013). NIPP maintains $\mathrm{EZH} 2$ phosphorylation and promoter occupancy at proliferation-related target genes. Nucleic Acids Res. 41, 842-854.

Nijenhuis, W., Vallardi, G., Teixeira, A., Kops, G. J. P. L. and Saurin, A. T. (2014) Negative feedback at kinetochores underlies a responsive spindle checkpoin signal. Nat. Cell Biol. 16, 1257-1264

Novak, B., Kapuy, O., Domingo-Sananes, M. R. and Tyson, J. J. (2010) Regulated protein kinases and phosphatases in cell cycle decisions. Curr. Opin. Cell Biol. 22, 801-808.

O’Connell, N., Nichols, S. R., Heroes, E., Beullens, M., Bollen, M., Peti, W. and Page, R. (2012). The molecular basis for substrate specificity of the nuclear NIPP1:PP1 holoenzyme. Structure 20, 1746-1756

Ohkura, H., Kinoshita, N., Miyatani, S., Toda, T. and Yanagida, M. (1989). The fission yeast dis2+ gene required for chromosome disjoining encodes one of two putative type 1 protein phosphatases. Cell 57, 997-1007.

Pinsky, B. A., Nelson, C. R. and Biggins, S. (2009). Protein phosphatase 1 regulates exit from the spindle checkpoint in budding yeast. Curr. Biol. 19, $1182-1187$.

Pores Fernando, A. T., Andrabi, S., Cizmecioglu, O., Zhu, C., Livingston, D. M., Higgins, J. M. G., Schaffhausen, B. S. and Roberts, T. M. (2014). Polyoma small $\mathrm{T}$ antigen triggers cell death via mitotic catastrophe. Oncogene 34, 1-10.

Qian, J., Lesage, B., Beullens, M., Van Eynde, A. and Bollen, M. (2011). PP1/ repo-man dephosphorylates mitotic histone $\mathrm{H} 3$ at T3 and regulates chromosomal aurora B targeting. Curr. Biol. 21, 766-773.

Qian, J., Winkler, C. and Bollen, M. (2013a). 4D-networking by mitotic phosphatases. Curr. Opin. Cell Biol. 25, 697-703.

Qian, J., Beullens, M., Lesage, B. and Bollen, M. (2013b). Aurora B defines its own chromosomal targeting by opposing the recruitment of the phosphatase scaffold Repo-Man. Curr. Biol. 23, 1136-1143.

Rosenberg, J. S., Cross, F. R. and Funabiki, H. (2011). KNL1/Spc105 recruits PP1 to silence the spindle assembly checkpoint. Curr. Biol. 21, 942-947.

Santaguida, S., Vernieri, C., Villa, F., Ciliberto, A. and Musacchio, A. (2011) Evidence that Aurora $B$ is implicated in spindle checkpoint signalling independently of error correction. EMBO J. 30, 1508-1519.

Sassoon, I., Severin, F. F., Andrews, P. D., Taba, M.-R., Kaplan, K. B., Ashford A. J., Stark, M. J. R., Sorger, P. K. and Hyman, A. A. (1999). Regulation of Saccharomyces cerevisiae kinetochores by the type 1 phosphatase Glc7p Genes Dev. 13, 545-555. 
Takagi, M., Nishiyama, Y., Taguchi, A. and Imamoto, N. (2014). Ki67 antigen contributes to the timely accumulation of protein phosphatase $1 \gamma$ on anaphase chromosomes. J. Biol. Chem. 289, 22877-22887.

Tang, N. H. and Toda, T. (2015). Alp7/TACC recruits kinesin-8-PP1 to the Ndc80 kinetochore protein for timely mitotic progression and chromosome movement. J. Cell Sci. 128, 354-363.

Tanuma, N., Kim, S.-E., Beullens, M., Tsubaki, Y., Mitsuhashi, S., Nomura, M. Kawamura, T., Isono, K., Koseki, H., Sato, M. et al. (2008). Nuclear inhibitor of protein phosphatase-1 (NIPP1) directs protein phosphatase-1 (PP1) to dephosphorylate the U2 small nuclear ribonucleoprotein particle (snRNP) component, spliceosome-associated protein 155 (Sap155). J. Biol. Chem. 283 35805-35814.

Topham, C. H. and Taylor, S. S. (2013). Mitosis and apoptosis: how is the balance set? Curr. Opin. Cell Biol. 25, 780-785.

Trinkle-Mulcahy, L., Andersen, J., Lam, Y. W., Moorhead, G., Mann, M. and Lamond, A. I. (2006). Repo-Man recruits PP1gamma to chromatin and is essential for cell viability. J. Cell Biol. 172, 679-692.

Vagnarelli, P., Ribeiro, S., Sennels, L., Sanchez-Pulido, L., de Lima Alves, F., Verheyen, T., Kelly, D. A., Ponting, C. P., Rappsilber, J. and Earnshaw, W. C. (2011). Repo-man coordinates chromosomal reorganization with nuclear envelope reassembly during mitotic exit. Dev. Cell 21, 328-342.

Van Dessel, N., Beke, L., Görnemann, J., Minnebo, N., Beullens, M., Tanuma, N., Shima, H., Van Eynde, A. and Bollen, M. (2010). The phosphatase interactor
NIPP1 regulates the occupancy of the histone methyltransferase EZH2 at Polycomb targets. Nucleic Acids Res. 38, 7500-7512.

Van Dessel, N., Boens, S., Lesage, B., Winkler, C., Görnemann, J., Van Eynde, A. and Bollen, M. (2015). Protein phosphatase PP1-NIPP1 activates mesenchymal genes in HeLa cells. FEBS Lett. 589, 1314-1321.

Vanoosthuyse, V. and Hardwick, K. G. (2009). A novel protein phosphatase 1dependent spindle checkpoint silencing mechanism. Curr. Biol. 19, 1176-1181.

Varmuza, S., Jurisicova, A., Okano, K., Hudson, J., Boekelheide, K. and Shipp

E. B. (1999). Spermiogenesis is impaired in mice bearing a targeted mutation in the protein phosphatase 1cgamma gene. Dev. Biol. 205, 98-110.

Voigt, W. (2005). Sulforhodamine B assay and chemosensitivity. In Methods in Molecular Medicine (ed. R. D. Blumenthal), pp. 39-47. Totowa, NJ: Humana Press, Inc.

Vulsteke, V., Beullens, M., Waelkens, E., Stalmans, W. and Bollen, M. (1997) Properties and phosphorylation sites of baculovirus-expressed nuclear inhibitor of protein phosphatase-1 (NIPP-1). J. Biol. Chem. 272, 32972-32978.

Wurzenberger, C. and Gerlich, D. W. (2011). Phosphatases: providing safe passage through mitotic exit. Nat. Rev. Mol. Cell Biol. 12, 469-482.

Wurzenberger, C., Held, M., Lampson, M. A., Poser, I., Hyman, A. A. and Gerlich, D. W. (2012). Sds22 and repo-man stabilize chromosome segregation by counteracting Aurora B on anaphase kinetochores. J. Cell Biol. 198, 173-183. 